\title{
Inoculation for successful establishment of Caucasian clover
}

\author{
HEATHER N. PATRICK, W.L. LOWTHER and K.D. TRAINOR \\ AgResearch, Invermay Agricultural Centre, Private Bag 50034, Mosgiel
}

\begin{abstract}
Results from oversowing trials in the tussock grasslands have shown that nodulation problems can limit the establishment of Caucasian clover (Trifolium ambiguum). They also strongly suggest that previously reported difficulties with establishment of Caucasian clover, in areas where white clover ( $T$. repens) had established sucessfully, were likely to be due to inoculation failures due to low numbers of rhizobia on the seed, or in the case of tetraploid cultivars, to the use of an unsatisfactory strain. With the tetraploid cultivar Treeline, inoculation with the recommended strain ICMP4074b resulted in low levels of effective seedling nodulation even with very high levels of rhizobia/seed at sowing (149 000). Treeline seedling nodulation was increased when inoculated with strain ICMP4073b, the approved strain for hexaploid cultivars, and the strain was effective at symbiotic nitrogen fixation. Effective seedling nodulation of both tetraploid Treeline and hexaploid Monaro cultivars inoculated with
\end{abstract} ICMP4073b-increased-as-the-number-of-rhizobia on the seed at sowing was increased. Low levels of seedling nodulation occurred when populations of rhizobia on the seed were in the range likely to be present when seed is slurry inoculated, or inoculated and pelleted and stored for several days before oversowing. To maximise effective nodulation, seed should be inoculated at least 5 times the recommended rate, with the incorporation of gum arabic in the slurry or pellet and oversown within one day.

Keywords: Caucasian clover, establishment, inoculation, nodulation, rhizobia, Trifolium ambiguum

\section{General introduction}

Caucasian clover (Trifolium ambiguum M. Bieb.) is known to persist and produce under drought and low input systems (Woodman et al. 1992; Yates 1993) but is considered difficult to establish (Lucas et al. 1981). Substandard inoculation is a possible reason for this problem as strains of rhizobia nodulating white clover either do not form nodules or form nodules that do not fix nitrogen on Caucasian clover (Parker \& Allan 1952) and inoculation with an effective strain of rhizobia is considered to be essential. Strain specificity can extend to differences within the hexaploid groups (Zorin \& Hely 1975). On the basis of nodulating ability and symbiotic nitrogen fixation under controlled glasshouse conditions, different strains are approved by Manaaki Whenua Landcare Research for each of the three ploidy levels in Caucasian clover. With oversowing, the inoculum rhizobia are exposed to severe environmental conditions and nodulation failure can limit establishment of legumes (Hely 1965). Under these conditions the strain of rhizobia used in the inoculant can influence seedling nodulation, and the selection on the basis of symbiotic nitrogen fixation in the laboratory is not necessarily relevant (Lowther \& Johnstone 1978).

In this paper we use current research findings and published research results to develop recommendations to maximise the establishment of Caucasian clover. Because of the reported specificity of different ploidy lines of Caucasian clover for rhizobia (Zorin \& Hely 1975) the nodulation of tetraploid and hexaploid lines have-been-investigated separately.

Tetraploid cultivars (e.g. Treeline)

\section{Introduction}

The strain of rhizobia approved by Manaaki Whenua Landcare Research for tetraploid Caucasian clover is ICMP4074b (a re-isolate of CC.286a). However, low rates of seedling nodulation occurred when the cultivar Treeline Caucasian clover (a tetraploid) inoculated with this strain was oversown (Lowther \& Patrick 1992) and it was concluded that further research was required to find a more suitable strain. To ensure nodulation of diploid, tetraploid and hexaploid Caucasian clovers, Dear \& Zorin (1985) used a mixture of strains CC23 1 a (=ICMP4072b), CC283b (=ICMP4073b) and CC286a (=ICMP4074b) on all plants.

In the experiment reported here, each of these strains has been used in a single strain peat inoculant applied at different rates onto Treeline Caucasian clover seeds to determine both the most suitable strain and the number of rhizobia required for effective nodulation in tussock grassland environments. 


\section{Materials and methods}

Symbiotic nitrogen fixation tests (Vincent 1970) were carried out on the 3 strains of rhizobia on Treeline Caucasian clover seedlings growing in agar tubes.

Individual inoculants of each strain prepared in the laboratory contained 3.8-4.1 x $10^{9}$ rhizobia/g peat. Seed of Treeline Caucasian clover was inoculated using 40\% gum arabic as an adhesive and lime as a coating. The inoculant was applied to seed at $0.33,1,3$ and 9 times the recommended rate for clovers of $9.6 \mathrm{~g}$ peat/ $\mathrm{kg}$ seed. Inoculated seed was stored at $10^{\circ} \mathrm{C}$ overnight then oversown, at the rate of $5 \mathbf{~} \mathbf{g} / \mathbf{h a}$ bare seed, onto undisturbed soil at 3 sites. Soils were high country yellow-brown earths with a vegetation cover typical of unimproved snow tussock environments (Mark 1965). The Crown Range site was at $1120 \mathrm{~m}$ with $\mathbf{p H}$ 5.1. The two sites on Waitiri Station were at $860 \mathrm{~m}$ and $950 \mathrm{~m}$ and $\mathrm{pH}$ of 5.2 and 5.3 respectively. Treatments were randomised in 4 replicate blocks on each site with plot size of $3 \times 2 \mathrm{~m}$. A basal dressing of $250 \mathrm{~kg} / \mathrm{ha}$ molybdic sulphur superphosphate $(0.05 \%$ Mo; $18 \% \mathbf{S} ; 8 \% \mathrm{P}$ ) was applied before oversowing and Miral (50 g/kg isazophos) was applied at $20 \mathrm{~kg} / \mathrm{ha}$ before seeds germinated.

Populations, of rhizobia were assessed in the peat inoculants by duplicate plate counts (Vincent 1970). The most probable numbers of rhizobialseed at sowing, one day after inoculation, were estimated by the plant infection method (Brockwell 1963) using IO-fold dilutions and 2 replicate counts. When seedlings reached the cotyledon/unifoliate leaf stage 40 seedlings in each plot, selected at random, were marked with wire markers and the number nodulated by the effective inoculant rhizobia was recorded 6 months after sowing. Because of the low levels of available soil-N, seedlings that were either non-nodulated or nodulated by ineffective rhizobia were small and yellow, or dead. Statistical evaluation of the effect of inoculant treatments on seedling nodulation was determined by an analysis of variance using sites as main plots and a rate by strain factorial as subplots.

\section{R e s u l t s}

No significant differences in symbiotic nitrogen fixation between the strains were detected. Populations of rhizobia on the seed at the time of sowing gave the required wide range of numbers with similar numbers from the, three strains at each individual inoculation level (Table 1)

There was no significant site effect on seedling nodulation and results presented in Figure 1 are the mean of the 3 sites.

Nodulation from strain ICMP4073b was significantly higher than from the other two strains at all
Table 1 Effect of strain and inoculation rate on number $\left(\times 10^{3}\right)^{1}$ of rhizobia/seed on Treeline Caucasian clover at oversowing, one day after inoculation.

\begin{tabular}{llll}
\hline Strain & $4074 b$ & $4072 b$ & $4073 b$ \\
\hline Rate & & & \\
0.3 & 4.2 & 1.2 & 3.3 \\
$1^{2}$ & 6.7 & 2.9 & 13.6 \\
3 & 56.2 & 51.2 & 42.7 \\
9 & 149 & 277.7 & 194.5 \\
\hline
\end{tabular}

1 Each estimate has a factor for 95\% fiducial limits of approximately $(x, \div) 3.5$

2 The recommended rate for clovers of $9.6 \mathrm{~g}$ peat $/ \mathrm{kg}$ seed.

Figure 1. Effect of strain of rhizobia and inoculation rate on the percentage of Treeline Caucasian clover seedlings effectively nodulated 6 months after sowing.

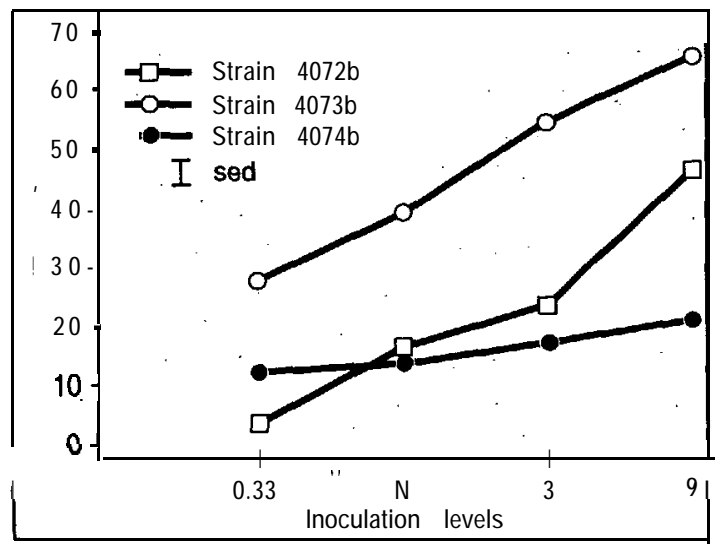

inoculation levels. Nodulation from strain ICMP4072b was significantly higher than from strain ICMP4074b at the highest inoculation level. Increasing the inoculation level progressively increased the percentage of seedlings nodulated but the magnitude of the response varied with the strain $(\mathrm{P}<0.001)$. There was a large increase in nodulation with strains ICMP4073b and ICMP4072b, in contrast to a small increase with strain ICMP4074b. Even with the best strain (ICMP4073b), increasing the inoculation level from the manufacturer's stipulated rate to 9 times the rate increased seedling nodulation by $69 \%$.

\section{Hexaploid cultivars (e.g. Monaro)}

Levels of seedling nodulation in Monaro Caucasian clover oversown on a range of tussock grassland sites were similar to white clover when seed was inoculated at a high rate $>3000$ rhizobia/seed at sowing; Lowther $\&$ Patrick 1992). They concluded that the strain of 
rhizobia used (ICMP4073b) was suitable for use under oversowing although the minimum population of rhizobia needed for satisfactory nodulation was not defined.

A later experiment (Patrick \& Lowther 1994), demonstrated that nodulation of oversown Monaro Caucasian clover was very responsive to inoculation level. Inoculant was applied to seed at a range of rates, in a gum arabic/lime pellet, and when sown one day after inoculation the number of rhizobia ranged from 200 to $260000 /$ seed. The percentage of seedlings nodulated progressively increased from $5 \%$ up to $66 \%$ as the number of rhizobia/seed increased (Figure 2). The number of seedlings established at the end of the first season showed a similar response (Figure 2) illustrating the importance of maximising seedling nodulation. Increasing the inoculation level from the recommended rate $(9.6 \mathrm{~g}$ peat inoculant $/ \mathrm{kg}$ seed; 23000 rhizobia/seed at sowing) to 6.3 times the rate $(60 \mathrm{~g}$ peat; 260000 rhizobia) resulted in a $64 \%$ increase in seedling nodulation when meaned over nine sites. Within individual sites, the response in seedling nodulation from increasing the inoculation level varied from $16 \%$ to $\mathbf{7 8 \%}$, demonstrating the need to evaluate inoculation technology over a range of sites representative of tussock grassland environments.

Figure 2 Effect of inoculation level on the percentage of seedlings effectively nodulated and plant establishment (no. $/ \mathrm{m}^{2}$ ) of Monaro Caucasian clover (from Patrick \& Lowther 1994).

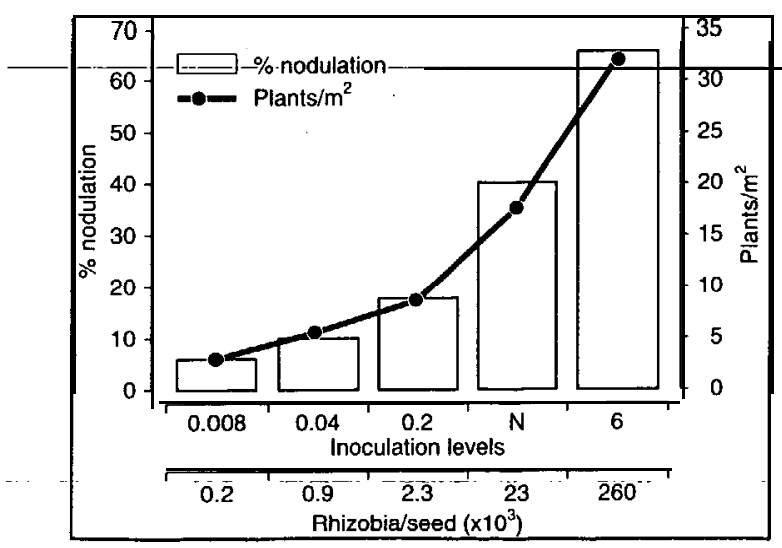

Lowther \& Patrick (1992) reported large differences in germination, nodulation and establishment of Monaro Caucasian clover on different sites and on one site there was a severe loss of seedlings in the first summer due to moisture stress. Similar variations were reported by Patrick \& Lowther (1994). At the high inoculation level, the number of established plants 7 months after sowing ranged from 0.5 to $45.8 / \mathrm{m}^{2}$ over all sites. The very low establishment was attributed to severe drought stress between the nodulation assessments 4 months after sowing and establishment counts after 7 months.

\section{General discussion}

It is clear that ICMP4074b, the currently approved strain for tetraploid Caucasian clover, is not suitable for use under oversowing conditions. Effective nodulation of seedlings from strain ICMP4073b was higher than that from ICMP4074b at all inoculation levels. Reasons for the poor performance of strain ICMP4074b are not clear. It was not related to poor survival of rhizobia on the seed between inoculation and oversowing as populations in the inoculant and on the seed at sowing were similar with both strains. The very small increase in seedling nodulation when the number of rhizobia on the seed was increased from 4200 to 149000 indicates a severe lack of saprophytic competence (i.e. nodulating ability) in strain ICMP4074b. The superiority of ICMP4073b in effectively nodulating oversown seedlings, coupled with effective symbiotic nitrogen fixation, indicates that this strain should be used to inoculate tetraploid cultivars of Caucasian clover, such as Treeline, when seed is oversown. The use of the same strain (ICMP4073b) for both tetraploid and hexaploid cultivars simplifies inoculant production and use for Caucasian clovers. Selection of strains of rhizobia for inoculant use based on their symbiotic nitrogen-fixing ability under controlled conditions is a technique that has been widely used. The results with the tetraploid Caucasian clover confirm the early caution of Chatel \& Greenwood (1973) that, in view of the complexity of the nodulation process, it is recommended that each Rhizobium-host plant-soil situation be studied separately, for it cannot be assumed on the basis of any previous work not related to the situation under question.

The large increase in effective seedling nodulation with both tetraploid and hexaploid Caucasian clovers from increasing the inoculation level from the manufacturer'srecommended rate to 3-6 times the-rate illustrates the potential to improve establishment under oversowing conditions by improving inoculant technology. Similar requirements for very high populations of rhizobia on the seed have been shown in Lotus comiculatus and marked differences in the ability of rhizobia to both survive on the seed before sowing and to nodulate the host plant were detected (Lowther \& Patrick 1994). Further evaluation of a wider range of strains of rhizobia to find more saprophytically competent strains is warranted to improve nodulation 
of Caucasian clover at inoculation levels likely to be experienced under practical conditions.

High levels of rhizobia per seed are necessary even when seed has been inoculated and pelleted using gum arabic and lime, and sown within one day of inoculation. In the absence of gum arabic, death of rhizobia on the seed is rapid even within a few hours of inoculation (Salema et al. 1982). The response to high inoculation levels could therefore expect to be enhanced when seed is slurry inoculated and/or sown after longer storage periods. The requirement for high populations of rhizobia on Caucasian seed at sowing indicates the standard of 300 rhizobia/seed developed for commercial white clover pellets (Johnston 1979) is not relevant for Caucasian clover.

The poor nodulation of Caucasian clover at low inoculation levels is a possible explanation of reported establishment difficulties (Lucas et al. 1981; Moorhead et al. 1994). In fact Moorhead et al. reported that about $80 \%$ of seedlings were small and yellow, with either no nodules or small pale nodules, 5 months after oversowing. Inoculation requirements of new legumes need to be evaluated during agronomic assessments. Although complete nodulation failures are easily recognisable, the influence of partial nodulation failures on legume establishment and yield is often overlooked. Low seedling establishment due to partial nodulation failure can lead to the underestimation of the yield potential of a legume under experimental conditions or to perceived poor productivity under farming conditions. The large increases in establishment possible from improved inoculation technology will result in enhanced productivity from oversown Caucasian clover and/or the use of lower seeding rates.

\section{Conclusions}

Previously reported problems with the establishment of Caucasian clover, in trials where white clover established successfully, would appear to be due to ineffective inoculation technology.

With tetraploid cultivars of Caucasian clover (e.g. Treeline) the approved strain of rhizobia was unsuitable and strain ICMP4073b $(=\mathrm{CC} 283 \mathrm{~b})$ is recommended for both tetraploid and hexaploid cultivars.

Even with strain ICMP4073b, establishment of oversown Caucasian clover is limited by low levels of effective seedling nodulation when seed is inoculated at the manufacturers recommended rate, even though relatively high populations of rhizobia were present on the seed at sowing. The nodulation problem would therefore appear to be due to the inability of the rhizobia to survive and multiply on or in the soil from sowing to infection of the seedling root.
To improve nodulation at more practical rates of inoculation, or with commercially pelleted seed, further research is required to select strains of rhizobia with better survival or multiplication characteristics,

\section{ACKNOWLEDGEMENTS}

Pyne Gould Guinness Ltd. and Challenge Seed Ltd. for supply of seed, and Mr Esmond Cook, Waitiri Station for use of land.

\section{REFERENCES}

Brockwell, J. 1963. Accuracy of a plant-infection technique for counting populations of Rhizobium trifolii. Applied microbiology I I: 377-383.

Chatel, D.L.; Greenwood, R.M. 1973. Differences between strains of Rhizobium trifolii in ability to colonize soil and plant roots in the absence of their specific host plants. Soil biology \& biochemistry 5: 809-813.

Dear, B.S.; Zorin, M. 1985. Persistence and productivity of Trifolium ambiguum M. Bieb. (Caucasian clover) in a high altitude region of south-eastern Australia. Australian journal of experimental agriculture and animal husbandry 25: 124-132.

Hely, F.W. 1965. Survival studies with Rhizobium trifolii on seed of Trifolium incamatum L. inoculated for aerial sowing. Australian journal of agricultural research 16: 575-589.

Johnson, D. 1979. Legumes. Seed inoculation. An introduction. Aglink FPP314. MAF, Wellington.

Lowther, W.L.; Johnstone, P.D. 1978. Effect of strains of Rhizobium trifolii on the establishment of oversown white clover (Trifolium repens). Soil biology \& biochemistry 10: 293-295.

Lowther, W.L.; Patrick, H.N. 1992. Seedling establishment characteristics of alternative legume species in tussock grassland environments. Proceedings of the New Zealand Grassland Association 54: 11 1114.

Lowther, W.L.; Patrick, H.N. 1994. Rhizobium strain requirements for improved nodulation of Lotus comiculatus. Soil biology \& biochemistry 26: In press

Lucas,R.J.; White, J.G.H.; Daly, G.T.; Jarvis, P.; Meijer, G. 1981. Lotus, white clover and Caucasian clover oversowing, Mesopatamia Station, South Canterbury. Proceedings of the New Zealand Grassland Association 42: 142- 151.

Mark, A.F. 1965. Vegetation and mountain climate. pp. 69-91. In Central Otago (R.G. Lister and R.P Hargreaves, Eds), Christchurch, New Zealand Geographic Society. 
Moorhead,A.J.E.; White, J.G.H.; Jarvis, P.; Lucas, R.J.; Sedcole, J.R. 1994. The effect of sowing method and fertiliser application on the establishment of Caucasian clover (Trifolium ambiguum M.Bieb.). Proceedings of the New Zealand Grassland Association 56: In Press.

Parker, D.T.; Allen, O.N. 1952. The nodulation status of Trifolium ambiguum. Proceedings of the Soil Science Society of America 16: 350-353.

Patrick, H.N.; Lowther, W.L. 1994. Influence of number of rhizobia on the nodulation and establishment of Trifolium ambiguum. Soil biology \& biochemistry 26: In press.

Salema, M.P.; Parker, C.A.; Kidby, D.K. 1982. Death of rhizobia on inoculated seed. Soil biology \& biochemistry 14: 13-14.
Vincent, J.M. 1970. A Manual for the Practical Study of the Root Nodule Bacteria. IBP Handbook 15. Oxford, Blackwell Scientific Publications.

Woodman, R.F.; Keoghan, J.M.; Allan, B.E. 1992. Pasture species for drought-prone lower slopes in the South Island high country. Proceedings of the NZ Grassland Association 54: 115- 120.

Yates, J.J. 1993. Growth and persistence of Trifolium ambiguum on 'high country' in Tasmania, Australia. Proceedings of the XVII International Grassland Congress. 1791-1792

Zorin, M.; Hely, F.W. 1975. Importance of homologous strains of Rhizobium trifolii in the domestication of hexaploid Trifolium ambiguum Bieb. Proceedings of the Australian Legume Nodulation Conference 5: $9 i-i v$. 